\title{
10
}

\section{Gendering, Degendering, Regendering}

Throughout the twentieth century and during the lives of the three generations explored in this book, a change in gender contracts has taken place. The dominant family model has changed from the agrarian family at the start of the century, where women and men contributed to the survival of the family within separate working spheres, to the male provider/female carer family of the middle of the century, where providing through gainful work was the responsibility of men and taking care of the home and the children was the responsibility of women. Later models were the dualearner family of the first gender battle in the 1970s and 1980s, where the norms about domestic work had changed without practice quite keeping up, and finally, the dual-earner/dual-carer family of the new millennium, where women and men try to share domestic work and childcare in a way they find personally fair, or, in some cases, acknowledge that it is not possible, given their preferences or conditions of the work market.

What has happened to gender in these processes? Where have they brought the project of gender equality? What place did the feelings of gender have in these processes of social transformation? In this final chapter I will attempt to summarise some of the answers that arise from the approach to gender and social transformation used in the book. I 
have followed Raymond Williams' recommendation to start with 'the whole way of life' when trying to understand changing cultural forms (see Chaps. 1 and 2). As a methodological consequence of this, I have not isolated feelings of gender from the context in which they emerged, but have gradually differentiated them out analytically as a particular social form. I will now put them back into the frame of the whole way of life where they belong and have their impact.

The dominant patterns of life choices of each generation make sense in the light of structural and political conditions: the agrarian family at the beginning of the century was a family of scarcity and no security net-it was about surviving, not justice. The male provider/female carer family of the mid-twentieth century could rely on increasing living standards and a policy that encouraged women to stay home. The dual-breadwinner family encountered the increasing demand of women in the workforce and an extended social security system. And finally the dual-earner/dual-carer family became possible with state-provided family-work schemes and the fact that women now were often more educated than men. The increasing pressure in the labour market also put limits on how far the sharing could go in this generation, especially in families where one or both parents worked in career jobs in the private sector. The different family form were interpreted, inspired and rationalised through dominating discourses of the time, especially the norm of obligation to one's family early in the century, the importance attached to the home, motherly care and safe childhoods in the post-war period, the discourses about women's rights and gender equality from the 1970s, and the increased emphasis on individualism towards the end of the century.

The main perspective in the book has been to explore to what degree the patterns of dominant life choices and the recognition of the discourses that went along with them also had an emotional sounding board, and to what extent one may say that the different family models were emotionally driven by feelings of gender or sometimes in tension with them. How did the changes in social gender contracts become something that women and men not only dutifully took part in, but also, to varying degrees, even wanted to contribute to? What are the emotional links between structure and agency at a given historical moment? The analysis has indicated that the emotional energy invested in life choices tends to 
be unequally distributed between women and men belonging to the same generations. This lack of simultaneity has produced tensions that may be seen as pressure towards change. In this way feelings of gender can be seen as active sources in processes of historical transformation.

\section{Emotional Links}

From their childhood, the oldest generation carried a deep mentality of work and feeling of obligations to their families. Work and family were fundamentally positive entities, which is not to say that they were without problems, hardships or sorrows. These feelings come in gendered versions connected to the hierarchy between men and women, the different valuation of their work, and their social positions, duties and entitlements. These asymmetries sometimes tinge the women's positive feelings about work and family with a hint of bitterness, especially towards other women who managed to get a larger share within this given hierarchical order. As we have seen, these experiences were processed in their relationships with their parents, where the women's idealisation of their fathers and ambivalence towards their mothers were stronger than the men's idealisation of their mothers and ambivalence towards their fathers. The outcome was gender identities and gendered subjectivities that existed in concurrence, but also in some tension with the changing sociocultural context. Especially at a historical moment where many signs conveyed that a new world was emerging, the father's connection to the outer world may have increased the young women's attachment to him and their ambivalence towards their mothers, whose authority was bound to the house and waning in the new times. This may also explain the more positive images of mothers in the middle classes where the mothers both had more time for the children and encouraged education and less obligation towards the family for both sons and daughters.

It is especially the asymmetry in feelings connected to femininity that represents an important emotional tension between women and men in this generation. As they came of age, the men's experiences of their own bodies constructed and confirmed the figure of the strong, working and heterosexual man, and of the exposed female body that could so easily 
become a victim not only of hard work, but also of the men's own sexuality. The women connected the reproductive aspects of their own bodies to the general curse of womankind, and silenced their fascination and desires for the wild and fun men. The men's feelings of guilt and moral compassion with the kind and too hardworking women are the most forceful emotional link identified in this generation's life choices. The men wanted their wives to stay at home so that they would not have as hard a life as their mothers, and the economic and political situation in this period made this possible. The men themselves were prepared to work hard to make it happen and at the same time to prove themselves as good and successful men. In this way they also indirectly kept up the invisible care they had received from their mothers during their childhood, including demarcating their own identities even more sharply from the female world. The price they paid was distance to their own children and a wife who complied with the arrangement with emotional reservation, indolence or silent discontent. Together they cooperated in their married life to refine the complementary gender order of nice women and responsible men. However, the emotional upgrading of femininity by the men from invisible mothers to caring wives ran opposite to the women's emotional downgrading of masculinity from fun fathers to boring providers.

The refined gender complementarity created by their parents contributed to a destabilising of the very same gender order in the next generation. The absent father and the available but often discontent mother frame the childhood of the middle generation in the middle of the century. The move from a rural to an urban setting took out the immediate meaningfulness of the mother's work in the home seen from the child's perspective, while (real) work and money became connected to men. This family arrangement created a rift in the social bond between sons and fathers and daughters and mothers. The fathers' work became more abstract as it was done outside the reach of the children, and the mothers did not need much help in their small, modern city departments. Children were sent out to play with each other instead, and both girls and boys were urged to prioritise their homework in the new co-ed school from this period. 'The policy for daughters' of the 1950s and 1960 s accentuated the rift between mothers and daughters in spite of being backed up by the mothers themselves. The relatively gender-neutral 
upbringing in post-war Scandinavia seems to have played a crucial role in the processes of change because it could connect to many other societal trends pointing in the same direction. The positive feelings connected to family and family obligations, duty and hard work lost their material and structural basis. The disidentifications and cross-identifications with parents in this generation of children lead to the psychological challenge of redefining the meaning of one's own gender through an identification with the other. Heterosexuality became a way for the men to confirm the masculine side of their identification once they came of age, which meant that the now-blurrier gender border became important to safeguard. The women put the heterosexual relationship in the service of liberation from their parents. This put them in a paradoxical situation where they exaggerated traditional femininity in order to become free. As young adults they recognised the futility of this strategy and instead headed for becoming individuals themselves.

The tension between women and men in this generation concerns how to interpret the gender border. The women tended to see it as a source of power and inequality and wanted to degender work and care, whereas the men could identify with care work only if the gender border was upheld with regard to money and sexuality. In the narratives of this generation the most forceful emotional link identified in their life choices is represented by the women who wanted to be different from their mothers and more like their fathers, and who had the expansion of the educational system and the increasing demand of female labour on their side. The men complied passively as they had a drive towards becoming better fathers than their own fathers had been, but they did not identify to the same degree with housework and joint responsibility for the home. They felt attacked by the connection the women made between gender and inequality, and feared that the women would disappear as attractive sexual objects. The women's project of becoming individuals could eventually draw on the arguments from the Women's Movement and the emerging gender-equality politics. The way forward was less clear for the men in this generation. What is a man if the sexual gender border disappears or he embodies more and more feminine psychological capacities? And what happened to the attendance he was accustomed to from his mother? The result was the dual-earner family, where the norm was to 
share work and care, but where the men's engagement was often more in principle than in practice, which ignited the many private and public gender battles in this generation. What complicated the situation for the women was also that their emotional ambivalence, sometimes even contempt, for traditional femininity as represented by their mothers and their attraction to male liberators sometimes interfered with their relationships with other women and also could make them unclear in their relationships with men.

In spite of the gender battles and divorces experienced in their childhood, the idea of family regained a positive emotional content in the youngest generation. They saw their family as a relational universe, a place for care and communication and sometimes even fun. The busy parents and the basically good terms that existed between children and parents moved the relationship towards partnership and mutual dependency rather than a relationship of authority. The children helped out more than in the previous generation as both parents worked outside the home, and they saw their parents as fallible and vulnerable human beings, sometimes with unfulfilled life dreams, burnouts and divorces. The gradual degendering of work and care made their emotional images of the parents and their own gender identities and gendered subjectivities more open. The mixture of individualism and gender was seen when this generation came of age: girls felt less obliged to fit into norms of passivity and femininity when it came to sexual encounters. However, in practice an active approach to sexuality risked being interpreted within a conventional gender framework and positioned them as either dependent or monstrous women.

The dominant emotional link identified in this generation's life choices, found both in the women and the men, is the trust in the parents and the basic feeling of being first and foremost an individual with all rights and possibilities at hand. They wanted to continue the family form of their parents, but with more fairness, fewer quarrels, less stress and fewer divorces. For the young women the choice of education was not made with regard to future family obligation as in the previous generation, and from an early age they were aware of the importance of sharing work in the family. For the men the division of work in their childhood families had more emotional impact on their expectations of family life. None of 
them questioned the norm of sharing, but handled it differently depending on their family experiences. The partnership this generation had experienced in their childhood families moved the gender battles towards a more principal norm of fairness where doing what one is best at or likes the best seems more important than sharing everything completely evenly. The tension between women and men in this generation is the concealed re-emergence of gendered structures within the framework of a partnership. The arrival of children was also a challenge in this generation, in addition to tougher conditions in the labour market in the new millennium. The problems were mostly interpreted in terms of their own ambivalences-wanting a career, to be a good parent, to keep fit and spend time with friends-rather than formulated as a critique of their partner. The general picture among the informants we meet at 40 is that men and women negotiate the outer demands as well as their inner splits in a more peaceful atmosphere with each other than was the case in the previous generation. They either divorce or try to find a way together where gender is not relevant as an argument for different contributions, but sometimes seen as a fact of their current life or even as an attractive difference when it comes to personal relations.

The emotional links had a different gender profile in different generations and they also led to new dilemmas of gender. The choice of the male provider/female carer family made most emotional sense for the men, and the gender dilemma that emerged in its wake raised the following question: what is a woman when she is not participating in the economy anymore? The choice of the dual-earner family made most emotional sense for the women and the dilemmas that now arose were: what is a man when he is doing domestic work and care work? What is a woman if she is not caring and kind? These new dilemmas established emotional tensions not only between women and men in these generations, but, as we saw, also within the individuals. In the youngest generation the choice of the dual-earner/dual-carer family seems to make emotional sense for both women and men, but not in exactly the same way, since their psychological point of departure and the cultural interpretation of their behaviours are different. The dilemmas that arose now are: what does individuality mean for personal gender and for gender structures? Can you be equal, yet different? Also here, life choices introduced new problems: old gender 
structures seemed to re-emerge behind the strong belief in individualised gender. The generational view shows that when old problems are solved, new and different sets of problems enter the stage. This represents the dynamic of change where gender is continuously reconfigured in the intersections of structural, political and emotional processes.

Looking for the emotional links is a way to grasp the prereflexive dimensions of agency (Adkins 2004b; McNay 2004; Silva 2005-see Chap. 1). The emotional link has both dynamic and adaptive sides. What it highlights is that the emotional drives have a historical/socialised form and are not lagging behind structural and political change. The emotional link is not only connected with the past, it also represents the sense of things in the present, and it anticipates the future to the extent that it resonates with new discourses and new structural life conditions (Aarseth 2009a). This reflects Raymond Williams' claim that no societal structures 'come first' in generating social change: 'New forms can flow from [a] particular form and extend in the whole organisation, which is in any case being constantly renewed and changed as unique individuals inherit and continue it' (Williams 2011: 125).

\section{Political Links}

The feelings of gender that gave direction to life choices and the experiences that followed from them also informed the attitudes to gender equality we found in women and men of the three generations. Norwegian surveys on attitudes to gender equality show an increasing support along age groups (Hansen and Slagsvold 2012; NOU 15 2012), but are the different generations and genders answering the same question in such surveys? Gender equality is an equivocal concept. It can mean justice-the right not to be discriminated against because of gender. It can mean equalitythat gender should be irrelevant to distributing tasks, duties, resources or privileges. It can be about individual freedom - the right to choose how to live one's life independently of gender. In Chaps. 5, 6 and 7, the attitudes to gender equality were described in terms of different dilemmas: for the oldest generation the gender complementarity model could be interpreted both as an expression of equity between men and women, and a 
hierarchical social order that cripples justice for women. For the middle generation the model of sharing raised questions about whether equality implies sameness or has room for difference. In the youngest generation it is rather the dilemma between gender equality as an approved norm and the belief in individual choice and freedom that is at stake. There are also differences between and within the generations in terms of in what areas gender equality is seen as relevant. It may concern skill sets and divisions of work, reproduction and parenthood, differences in personality and preferences, sexual norms and behaviour, style and appearances. Differences may be seen as natural or cultural, and as worth keeping or changing. Models of gender difference may survive within a general embrace of gender equality: ideas about fundamental biological or psychological differences between women and men, or that complementarity in some areas of life is practical or desirable. Thus, equality and difference, justice and freedom exist in different dimensions - and they move, disappear and re-appear in different places and different disguises. The positions on gender equality we find in the different generation are based on practices, cultural norms and feelings of gender, and these do not always pull in the same direction.

For the oldest men, modern gender equality is at odds with their own life project since it makes their own form of masculinity—and the sacrifices that came with it-worthless, and moreover makes their idealised wives a target for critique. They are occupied with the crumbling moral order in society and their critique of modern times is condensed in their worry about the increasing number of divorces. They defend the mild and kind motherliness of the feminine carer against new ideas of women becoming like men. For the oldest women, the belief in gender complementarity in work, care, skills and personalities is not so emotionally hard-wired as for the men. Women with agrarian roots rather associate the question with the asymmetries and injustice in the gender order of their childhood. The middle-class women's focus is on equal capabilities in women and men, which they think ought to be more acknowledged. Whereas the men in this generation are loyal to their trust in gender complementarity, the women are stuck in the tension between, on the one hand, beliefs in justice of gender equality and, on the other, the strong social norm of gender complementarity and gender hierarchy that they 
have lived with. What women and men in this generation agree on is natural differences in sexual behaviour and that the body is a women's issue. As we saw, both women and men in this generation adjust their attitudes somewhat to the new practices of their children and grandchildren, but it is not difficult to see the connection between their principal view and their generational feelings of gender.

The idea of gender equality has more emotional appeal in the middle generation, where many of the men want to develop their relational capacities and become more present fathers than their own had been, and many of the women want to get away from their mothers and have a more independent life. The views of the women in this generation vary from a radical stand for women's right to self-determination and against individual discrimination, to a general support of gender-equality policies addressing social rights on the group level, and to a more pragmatic individual approach, where issues of equality come second to what is convenient or necessary for the family. Whether the fight for gender equality should take place mainly inside or outside the family is also a dividing line. For the men the discourse of gender equality in work and care is a much more palatable idea than the discourse of feminism and women's rights which puts the blame on them. Yet, the problem of following up the housework in practice and the importance they attach to the sexual gender difference make almost all men in this generation somewhat awkward when they address the issue of gender equality, even though they support it in principle. There is a time lag, but also partly a different agenda between women and men here: for the men gender equality is about getting close to their children and preventing quarrels with their wives; for the women it is about the fairness of sharing and getting the same opportunities as men in the labour market. For the radical women it is also an engagement against the sexualisation and objectification of the female body.

In the youngest generation the emotional appeal of gender equality has diminished for both women and men, not because they are against the idea, but because to a large extent they find that it has already been achieved with regard to work, care, skills and sexual norms. They feel more like individuals than as gender, and therefore only reluctantly identify with the gender categories that are the foundation of any gender- 
equality policy. But since they believe gender equality is already a fact, they also become quite upset when they realise that this is not always the case. In the context of the workplace this applies to both women and men; in the context of the family the reaction comes only from women. Yet, the women's critique is often moderated by their own distaste for rigid regimes and their belief that people should do what they are best at and enjoy. This leads to a less ideological but perhaps also more disguised gender battle where, for instance, hiring au pairs and cleaners may help to keep up the belief in modern gender equality in the families that can afford them. The structural levels of gender discrimination are not always addressed or seen as something that is difficult to combat, like the work conditions in the private sector, where more of the men than the women work. Subtle discriminatory mechanisms escape the attention of even the most alert: Hilde and Pia were well aware at 30 that gender gaps in salaries are often a threat to attaining gender equality at home, but they did not connect it to the opposite problem, which they had not experienced at that time, but which Guro and Tonje told us about: that women who make more money than their male partners risk threatening their partners' feeling of masculinity. This complex cultural web makes gender equality much more of a demanding balancing act for women than for men. This dilemma is further accentuated as both men and women seem to appreciate gender differences in some areas. They tend to see feminists as over-the-top aggressive and ignorant of bodily issues and the pleasurable aspects of personal gender differences. They also tend to find genderequality policies boring and preoccupied with insignificant details.

The changing feelings and norms of gender are intertwined with processes of social mobility. The least engagement with, or even resistance towards, modern gender-equality discourses is found in the few workingclass chains where there is no social mobility across the three generations: the female chain of Borghild, Berit and Beate and the male chain Gunnar, Geir and Glenn. In these working-class families sharing the work is more of a practical matter-which was seen both in the relatively fair sharing of work between Berit and her husband with regard to their work hours, and in Gunnar and Geir's 'knack with children', combined with Geir's shunning of housework and women's tedious talk. In the middle-class families it is a more ideological matter and traces of traditional gender 
arrangements are felt to be old-fashioned and embarrassing, and must either be openly opposed, explained away or disguised (cf. Haavind $1984 a, b)$. It may also be the case that gender differences have a different emotional foundation with regard to class. In the middle-class families in the youngest generation, gender identities are mainly expressed through leisure activities, consumption and aesthetics, whereas work, care and household are losing ground as bases for gender identity projects. ${ }^{1}$ In the working-class families, gender identities seem to be more dependent of the work division in the family and this pattern may also continue into the next generation in cases of upward social mobility. This was the case with Kine, who had a high-powered job and fought for gender equality at work, but suddenly, as she approached 40, felt that she had become unfeminine and her partner unattractive as a man, which she connected to their untraditional gender arrangements at home. The Swedish historian Ronny Ambjörnsson says that gender often gets in a squeeze in class journeys (Ambjörnsson 1996/2005: 27). This may explain the overlaps of feelings of gender between the class of the childhood family and the adult family of a new class. In our sample this overlap seems to be more prominent if both spouses grew up in the same class and made similar class journeys. We also observed this in the oldest generation when a young rural couple settled in the city. In those cases the agrarian culture was more resistant to modern urban culture than in cases where one person grew up in the city and the other in the countryside (Nielsen and Rudberg 2006). Thus, the attitudes to gender-equality policies are connected in complex ways to gender, generation, generational relations, class and social mobility.

Degendering and regendering processes are not univocal; there may be contradictions between practices, norms and emotions. Gender norms may lose credibility, but practice may still be gendered. Housework was an example of this. The housework became less gendered in the middle generation, partly because mothers now combined it with paid work out-

\footnotetext{
${ }^{1}$ A pertinent question is whether gendered work and care are actually gaining ground again in the new reincarnation of stay-at-home mothers, which has become a media hype in recent years. So far, however, it seems in practice to be only an upper-class phenomenon in Norway (see Aarseth 2015) and is not visible, for instance, in terms of changes in figures of women's employment. At any rate, this idea did not seem to have any appeal among the informants we talked to in 2011.
} 
side the family and partly because the other family members participated or thought they ought to. This could lead to a masking of still-gendered practices, but it could also contribute to a degendering on a symbolic level when such gendered practices were interpreted as an expression of individual preferences. Yet when work and care are distributed according to individual preferences, they are also often regendered again because of habits, distribution of skills or feelings of gender. Individualistic explanations of gendered choices may be seen both as an unaware reproduction of structures and as producing new understandings that gradually also affect practice. Degendering and regendering may also take place in different areas, such as a regendering of aesthetic imaginaries running in parallel to a degendering of most other areas in life.

Across the generations it emerges that positive attitudes to gender equality understood as equal treatment and equal possibilities are for the women in all three generations closely linked to higher education and often also to encouragement from their mothers to get an education, in addition to experiences of injustice in their lives. For the men in our study the link to education is not as clear. Here a positive identification with the mother, the division of work in their own marriages and whether they have daughters seem to be more crucial. Gender equality is not as pressing an issue for men as it is for women; they go along with it if needed or if they see their interests in it. However, as we have seen, practice has in itself a transformative potential: the more men participate in childcare and household tasks, the more skills they gain and the more they tend to enjoy it. Helene Aarseth's longitudinal study of families sharing a gender-equality project indicates a dynamic process: it may start as a morally driven project about equality and justice, but eventually develops into a project of joint engagement and individual desire- and in this process the different tasks that are undertaken in the family are also increasingly degendered (Aarseth 2009b; see also Plantin et al. 2003). Aarseth's point is that real change happens only when the project has moved from being an external demand to being an internally driven project that feels emotionally meaningful to the participants. This point echoes Raymond Williams' words that 'the absolute test by which revolution can be distinguished, is the change in the form of activity of a society, in its deepest structure of relationships and feelings' (Williams 1977: 420). However, it 
also implies that feelings of gender may sometimes delay the revolution or that new feelings may be produced at a different pace and through different types of situations than political identities.

What is striking when we look back at the interviews with the youngest generation at 30 is that many of the gender issues raised here received increasing public and political attention in the following years. In the first decade of the new millennium more attention was given to the unsolved problems or unintended negative consequences of the official genderequality policies (NOU 15 2012): that life in the dual-earner/dual-carer family had become too stressful, that women's own priorities also contributed to the lack of equality, that there was too little focus on men's situation, that more attention in society should be given to care values and not only to what is profitable, and that gender equality in work and care could be combined with an appreciation of gender differences in other aspects of life. In different ways, our youngest informants voiced the demands of their generation for more personal choice and differentiation in gender politics already in 2001 (Melby et al. 2008; Nielsen 2004). Among the men, the wish to be at home and take care of their children or the insistence that gender equality should 'go both ways' was already present in many of the interviews at 18 . Thus, these issues seem to emerge from everyday experience and this may be seen as one of the conditions for their political articulation. Political identities are also based on feelings of gender. It is not possible from our sample to decide whether there was a similar psychological readiness for new policies in the two older generations. However, from what we know of their life experiences, it seems more than likely that the educational policies in the 1960s and 1970s had a clear emotional appeal in the older generation, particularly for the women. Correspondingly, the gender-equality policies introduced in the 1970 s and 1980s had a similarly strong emotional appeal in the normal chaos of love that we described for the middle generations as adults, including the men's emotional readiness to become more present fathers.

As we saw in Chap. 9, the three generations reflect the theories of gender psychology of their respective times. The same could be said about the women and the different historical approaches of feminism. With their emphasis on justice, equality and freedom, there is an affinity to the three 'waves' of feminism: from liberal and social feminism in the first-wave Women's Movement, to radical feminism in the second wave, and the 
post- or individual feminism in the third wave (Holst 2009). What the study of the three generations shows is that the influence may go both ways. Political mobilisation is not necessarily prior to processes of mental change in a population, but the political articulation can catch and help articulate vague feelings. The difference between the women in the oldest and middle generations illustrates this: there was no political movement to catch the discontent of the older women, positioned as they were between the first and second waves of feminist articulations (and, from what we know, none of the interviewees read The Second Sex, which came out in 1949). In contrast, the family policy of the time helped the men articulate their feelings of gender in a way that silenced the women and made them express their discontent in bitter remarks or in their unenthusiastic complicity as housewives. In the middle generation the Women's Movement helped articulate the frustration of the women and gave it direction. And this point of intersection between feelings and politics was again framed by economic structures of increased wealth and expanding higher education. The sensation of new normalities was based in politics, structures, feelings and everyday practices.

\section{Gender Links}

In the youngest generation women and men seem to have more similar projects, more of the same thinking about freedom and individuality, more shared beliefs that gender no longer matters and also more of the same appreciation of sexual difference in limited areas of life. However, there are also asymmetries in how this is achieved and the dilemmas that come with it. It is common to think that, due to the gender hierarchy, it is easier for women to appropriate 'masculine' values and activities than for men to appropriate 'feminine' values and activities. To some extent we have also seen this in the analyses: it was more culturally acceptable for women to do men's work in the oldest generation than for men to do women's work. It was easier for the women in the middle generation to take over and degender their fathers' skills and knowledge than for the men to take over and degender their mothers' skills and knowledge. In the youngest generation girls were more encouraged to play football than boys were to dance ballet. However, in the youngest generation the opposite is also the case: it appears to be easier for the young men to extend 
their masculinities with 'feminine' qualities like care and attendance to bodily appearance than for young women to become fully acknowledged as subjects of desire and power. The cultural and psychological sluggishness connected to bodies and sexuality for women more than for men keeps interfering in the degendered areas of work and care in ways that are not part of their wish to keep sexual difference alive in other areas. The young women often must walk a fine line in order not to be gendered too much or too little. They are facing dilemmas here that are more or less unknown to the men: take care not to dress up neither too femininely so you are not taken seriously at work or in a way that makes people see you as a boring neither-nor. Take care not to speak up so much that you are seen as dominant and aggressive, but not so little that you are seen as a dull woman. Take care that you do not earn less than your partner so that you will be left with the care work in the family, but do not earn more than him so that he will feel pussy-whipped either. The tribute to equality, individuality and free choice often comes with an unacknowledged contempt for traditional femininity that we also find, directly or indirectly, in both women and men in the youngest generation. The empathy with fragile masculinity that we saw in both the oldest and the youngest generations of women stands in striking contrast to the contempt for women who are gendered either too little or too much. The young women shun group identifications on the basis of gender more than is the case for the young men. The increased individualism in modern societies is in this way a double-edged sword for women in the sense that it simultaneously liberates them from old limits and inequalities and invites them to take part in something that is culturally and psychologically deeply coded as masculine.

Feminist sociologists have debated whether individualisation is a phenomenon that privileges men and the middle classes more than women and the working classes or whether individualisation take on different forms (Jamieson 1998; Skeggs 2003; Roseneil 2007). Beck and Beck-Gersheim's claim that modernisation gave the female biography an 'individualisation boost' (2002: 55) is on the one hand undeniably right: gender differences have become less defined and legitimised by religion, tradition and family, and women's lives have changed more than men's in the last century, especially in the areas they mention (education, work, 
sexuality and relationships). On the other hand, it is also the case that the combination of gender and individuality is not so straightforward for women as it is for men. For women, being an individual and being gendered tend to be two separate identities that are difficult to inhabit at the same time. For men, an extended masculinity becomes part of their individuality more easily. This appears to be one of the cultural bedrocks of gender. Already in their narrative styles we saw more emphasis on self-development among the men than was the case with the women. The middle generation struggled with integrating the 'feminine' values they identified with in their mothers, but many of them actually used the newly appropriated qualities of emotionality to extend their masculine selves, for instance, by channelling them into projects of self-development and work qualifications, as much as they used them to take responsibility for relationships with others. To be 'yourself' was an important value among all in the youngest generation when we interviewed them at 18 , but while among the middle-class boys this meant standing out as unique and unpredictable individuals, it meant being one's 'authentic self' for the middle-class girls, and for the working-class girls and boys meant being relaxed and tolerant. There is not necessarily any contradiction between using emotional skills for personal development, at work or in relationships with others, but there seem to be some gendered patterns in terms of how the emotionality within these areas connects and is displayed. In spite of the prevalence of 'new men', political scientists have also observed an increasing gender gap in the political attitudes of young people, where more young women than young men adhere to the basic values of the welfare state like social reform and economic solidarity (Christensen 1994; Øia 2011). The young women represent a 'relational individualism'2 $^{2}$ to a higher degree, where their relational capacities are used to increase their feelings of responsibility in society at large rather than to engage in strategic self-development.

\footnotetext{
${ }^{2}$ The concept of 'relational individualism' is inspired by Nancy Chodorow, who first used it in an article from 1986 with the same name (Chodorow 1989). Chodorow used the concept in order to distinguish an object-relational psychoanalytic understanding of the self from a more orthodox Freudian version of autonomy. My use of the concept here is broader, as I also include the moral and political dilemmas of cultural individualisation.
} 
The characteristic switching in the youngest generation between gender as dichotomy and gender as irrelevant may illustrate a tension between, on the one hand, gender as a dichotomous structure in our language and thinking where it is almost unavoidable to automatically 'gender' opposing qualities, and, on the other hand, an experience of increasing irrelevance of gender in practice. However, it may also testify to gender having become a more flexible dimension psychologically and through this also less substantial and threatening. It is difficult to see the appreciation of sexual difference within certain limits as only products of normative commands, backlashes or defensive reactions in the youngest generation. Gender as 'soft assembly' may be a historical product: 'Gender may in some contexts be thick and reified, as plausible real as anything in our character. At other moments gender may seem porous and insubstantial' (Harris 2002: 104). Muriel Dimen argues that the solution to the problem of splitting is not merely remembering the other pole, but 'being able to inhabit the space between, to tolerate and even enjoy the paradox of simultaneity' (Dimen 2002: 56). What I would add to this is that there are not only new spaces between the two poles, but also non-gendered spaces where the poles disappear because they are simply no longer experienced as relevant.

This addresses the question I posed in Chap. 1 about the relationship between destabilising a category and weakening its significance in different areas of life. Increased equality leads to a weakening of gender norms or makes the category of gender less important, constraining and exclusionary in some areas. This does not imply that sexual difference disappears, but different sexual preferences based on sexual difference may be experienced as more personal and less normatively constrained choices. The wish for sexual difference in heterosexual attraction expressed by many in the youngest generation is not claimed as general, unitary, recommendable or normative, but as a personal preference (until further notice). Within the youngest generation's individualist frame of thinking, it is rather a claim that everyone should do as they like, and what one likes may vary. Thus, the connection between gender norms and desire is loosened. Heterosexual choice becomes one of a number of choices. This does of course not remove the still-prevalent discriminatory attitudes and structural disadvantages of non-normative groups in society with a magical touch, but it indicates that heterosexuality may also be understood and practised within a post-heter- 
onormative frame. The focus in this book has been the patterns of feelings of people living different kinds of 'normalised' lives at different points in time, but changes in norms do not happen in isolation from what goes on within other groups in society. Norway has become a multi-ethnic society since we did our original interviews in 1991. Sexual minority groups have become more visible, and the majority groups have become more aware and in most cases more acknowledging of diversity. The intimate lives of people from different groups also intersect more. Just looking at the eight informants we interviewed in 2011, two have non-Norwegian partners, four have worked outside Norway for longer periods of time, one has experienced that someone in the close family came out as bisexual, one has had a brief homosexual experience, one had a best friend who was a lesbian, and one said he liked to flirt with both women and men. This is a huge change compared with the two older generations in my sample. The increased openness to homosexual and bisexual impulses in themselves may be connected to the multi-gendered selves produced through their generational biographies, as well as to increased contact with people living non-normative lives, and to the new discourses on queer rights in popular culture and politics. This also shows that there are no strict borders between the different groups, and that both straight and queer people contribute to changes in gender norms and intimate life (Roseneil 2007). To return to Raymond Williams once again: new forms can flow from any particular place and extend into the whole organisation.

In 1991, the same year we did our interviews with the three generations analysed in this book, the Anglo-American relational psychoanalyst Virginia Goldner wrote the following, inspired by Judith Butler's Gender Trouble that had come out the previous year:

The cultural matrix that sustains the illusion of two coherent gender identities prohibits and pathologizes any gender-incongruent act, state, impulse, or mood, as well as any identity structure in which gender or sexuality is not congruent with biological sex. Thus, those genders and sexualities that fail to conform to norms of cultural intelligibility appear only as developmental failures or logical impossibilities. (Goldner 1991: 254) 
In spite of the undeniable presence of sluggish psychological and cultural structures, the multiple gender identifications in the youngest generation cannot easily be fitted into this image of looming gender binaries. Judging from the changes that emerge from the analysis of the feelings of gender in the three generations, the cultural matrix mentioned above hardly describes young people's lives in Norway in 1991. Not only did we see more multigendered identities and subjectivities in the youngest generation, but also that this extension had emerged gradually through complex social processes during the twentieth century. Activities and norms connected to education, work, care and ways of being and doing, have beyond doubt become less gendered. Degendering has also taken place with regard to bodily preoccupation and sexual norms and practices, but here the sluggish aspects are more pronounced. The cultural codes cannot explain why change happens, only what hampers and delays it. They do not say anything about historical conditions or the subjective motivations for taking the small steps that gradually accumulate into historical change. The many ways in which cultural codes are lived and handled are much more ambiguous than the codes themselves.

Against this claim it could be argued that the sample I have analysed lives comfortably within what Goldner calls the 'norms of cultural intelligibility'. However, the point is that in this process the norms themselves have become extended and more flexible, psychologically as well as culturally. The situation fits better with what Lynne Layton, with reference to Homi Bhabha, wrote in 1998: 'the "new soul" ... emerges from a process of inhabiting a sexed body and identifying with men and women in such a way as to displace timeworn histories of hegemonic masculinity and femininity' (1998: 190). Maybe we are not quite there yet, but a considerable step has been taken in this direction during the three generations we have followed.

Open Access This chapter is distributed under the terms of the Creative Commons Attribution 4.0 International License (http://creativecommons.org/licenses/by/4.0/), which permits use, duplication, adaptation, distribution, and reproduction in any medium or format, as long as you give appropriate credit to the original author(s) and the source, a link is provided to the Creative Commons license, and any changes made are indicated.

The images or other third party material in this chapter are included in the chapter's Creative Commons license, unless indicated otherwise in the credit line; if such material is not included in the chapter's Creative Commons license and the respective action is not permitted by statutory regulation, users will need to obtain permission from the license holder to duplicate, adapt or reproduce the material.

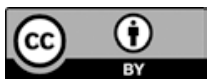

